\title{
Caro, I. (ed.) 2014. Del diálogo a la alianza de civilizaciones. Visiones desde el Cono Sur latinoamericano. Santiago, Chile: RIL editores.
}

\author{
Alejandro Corder Tapia* \\ Universidad Arturo Prat, Iquique, Chile
}

El libro que reseño a continuación es fruto del persistente y sistemático trabajo del Dr. Isaac Caro por construir un espacio de reflexión y análisis en torno al diálogo religioso y civilizacional en América Latina, motivación que, ligada a un proyecto de investigación Fondecyt, impulsa la creación de este libro. Este trabajo está compuesto por un conjunto de artículos (nueve en total) que dan cuenta de las miradas, investigaciones y experiencias en torno al diálogo en América Latina. La diversidad de autores y sus respectivas adscripciones académicas e incluso religiosas hacen que cada capítulo sea no solo un ejercicio de reflexión intelectual sino también una apuesta por construir espacios de diálogo, ya sea cultural, religioso o civilizacional.

Este libro está dividido en tres secciones. La primera de ellas se titula "Aportes del mundo judío, el mundo árabe y el islam: tres visiones académicas", y está compuesta por los trabajos de la académica de la Universidad de Chile Dra. Ana María Tapia, el segundo del académico Lorenzo Agar, de la misma universidad, y Diego Melo de la Universidad Adolfo Ibáñez. El primer trabajo, de Ana María Tapia, constituye una reflexión sobre el aporte del mundo judío a los procesos de diálogo y entendimiento religioso y civilizacional, particularmente en el Cono Sur latinoamericano. Pasando por revisiones bíblicas desde la historia antigua de Israel hasta nuestros días, la Dra. Tapia sitúa algunos principios o elementos distintivos que permiten relacionar los fundamentos religiosos del judaísmo con los sistema democráticos imperante actualmente. Relevando la importancia de figuras políticas e intelectuales de origen judío, se intenta relacionar sus aportes con los procesos de entendimiento entre confesiones judías, cristianas y también islámicas, poniendo especial énfasis en la importancia y necesidad de realzar el derecho de vivir "de acuerdo a sus valores y principios, a adorar al Dios en el que cree (...) a condición de que no se discrimine ni se dañe a los demás".

Sociólogo. Licenciado en Sociología, Universidad Arturo Prat. Diploma de Estudios Avanzados, Universidad del País Vasco. Doctor(c) en Derecho, Universidad del País Vasco. Investigador del Instituto de Estudios Internacionales INTE, Universidad Arturo Prat. Correo electrónico: lcorder@unap.cl 
El trabajo del profesor Agar, "La población de origen árabe en Latinoamérica: reflexiones sobre cohesión social comunitaria", da cuenta de los procesos de inserción social que han vivido las poblaciones migrantes árabes en América Latina con particular atención a Chile. Agar da cuenta de las características mundiales de la migración árabe a nuestro continente (fundamentalmente sirios y libaneses, a excepción de Chile, que se caracterizan por ser palestinos de Belén y Beit Yala) para situar en ese contexto las particularidades de sus procesos migratorios y de inserción social. De esta forma destaca aspectos relacionados con la percepción de las comunidades nacionales acerca de los migrantes árabes, sus prejuicios y la construcción de discursos hegemónicos que rechazaban su arribo a los distintos países. Pese a estas dificultades iniciales, Agar destaca los esfuerzos de las distintas comunidades por insertarse en las actividades económicas (destacando el comercio) y el emprendimiento de actividades productivas del ámbito textil. El texto también da cuenta y destaca los procesos de incorporación cultural de las primeras y segundas generaciones a la comunidad nacional, produciéndose procesos de integración social y cultural, que a medida que avanzan generacionalmente las poblaciones migrantes, se producen procesos de adaptación y apropiación del capital cultural de la sociedad de acogida para facilitar los proceso de integración, traducidos por ejemplo en matrimonios mixtos o profesiones liberales que facilitarán la cohesión social de las comunidades migrantes.

Agar concluye que, a diferencia de las primeras poblaciones árabes llegadas a nuestro continente, las nuevas generaciones de descendientes más recientes se caracterizan por apelar y ejercer la pluralidad cultural más que la aculturación o la invisibilidad de sus raíces.

El trabajo del profesor Melo, "Islam, una visión académica", constituye un ejercicio analítico e histórico por situar el conocimiento del mundo islámico por parte de Occidente, particularmente a través de las transformaciones que empiezan a operar a partir de los atentados terroristas de septiembre del año 2001 en Estados Unidos de Norteamérica. A partir de los hechos señalados, el autor da cuenta de la innumerable bibliografía que comienza a emerger respecto al mundo musulmán, sus fundamentos religiosos y culturales, pero que, a juicio de Melo, se caracterizan por ser construcciones sesgadas y monolíticas respecto al islam. Melo destaca también la relevancia que adquiere, a veces sin mucho juicio crítico por parte de sus lectores, las tesis de choque de civilizaciones propuesta por Huntington, obra que constituye un referente muy citado en los análisis académicos occidentales respecto al islam. Al mismo tiempo, el autor de este capítulo también destaca la situación contraria en que el mundo musulmán construye miradas monolíticas respecto a Occidente, como si también nuestra cultura no tuviera diferencias 
sustantivas entre mundos tan distintos como el europeo y el latinoamericano. El análisis continúa con una reflexión en torno a los factores históricos que permiten reconstruir la noción que se elabora en el mundo musulmán respecto a Occidente, un sentimiento de insatisfacción respecto a la cultura occidental, rechazo que se acrecienta con la emergencia de lo que se ha llamado "primavera árabe". Así se dan cuenta de una serie de hechos históricos que permiten contextualizar la noción que tanto Occidente como el mundo árabe musulmán tienen el uno del otro en distintos periodos de la historia.

Melo releva que así como Occidente no es una cultura monolítica sin diversidad, el mundo musulmán tampoco es una unidad sin particularidades, que en distintos períodos ha tenido mayor o menor vocación de diálogo y tolerancia al "otro", apelando a que esas desconfianzas mutuas y, por tanto, las posibilidades de diálogo, puedan superarse, siguiendo a Muhammad Jatami, apelando al respeto por las identidades independientes de la otra parte y su independencia e identidad ideológica y cultural.

La segunda parte del libro se compone de tres trabajos en que se desarrolla la perspectiva religiosa del diálogo. El primer capítulo es del rabino Chaim Koritzinsky, quien siguiendo las reflexiones del filósofo y activista social David Hartman, da cuenta de que las propias escrituras sagradas tienen como principio el respeto al pluralismo y a la (co)existencia de creencias distintas a la judía, pero más aún, señala Koritzinsky, "solo podemos existir porque convivimos con los demás [otros pueblos]. Por lo tanto, es fundamental poder convivir y dialogar con diferentes creencias, cada cual es escogida para profesar su propia fe".

El segundo capítulo está escrito por el sacerdote Fernando Verdugo, quien desde la perspectiva del cristianismo reflexiona en torno a los aportes que puede hacer su credo en América Latina a la búsqueda de la paz y el entendimiento religioso. Así, Verdugo analiza el contexto de transformaciones de orden mundial que se dan en el marco del proceso de globalización y se pregunta cómo es posible que la fe cristiana ejerza su potencial liberador y humanizador en este continente. Esta pregunta lo lleva a plantear el argumento de que el cristianismo puede contribuir a ello si se asume que la religión no debe leerse como un discurso absoluto, pues esto generará temor al diálogo o al intercambio con otras culturas y credos. Verdugo sostiene además que es necesario rescatar la figura de Jesús y su mensaje de búsqueda de justicia y de reencuentro con Dios. Resulta también un aspecto relevante de esta reflexión la apuesta que hace Verdugo por "discernir el Espíritu en la historia", esto es, comprender la relevancia de la fe para la comprensión del momento histórico que estamos viviendo y de cómo el ejercicio religioso puede ayudar 
a darle sentido a las transformaciones de hoy, tal como lo fue en su momento el Concilio Ecuménico Vaticano II.

"Una visión de unidad desde la perspectiva del sufismo" es el tercer capítulo de Jaime Searle de la comunidad sufí Halveti-Jerrahi de Santiago de Chile. Aquí se entregan antecedentes sobre las características del sufismo al interior del islam, su surgimiento y las características históricas de la orden Halveti-Jerrahi. Más adelante se analiza la búsqueda de sentido como una actividad inherente al ser humano y cómo desde esa búsqueda tiene cabida el reconocimiento de otro distinto a nuestras creencias. El aspecto central es que el sufismo permite, a través del conocimiento, dar sentido a nuestra existencia y comprender la relación que dicha existencia tiene con Dios. Cabe destacar que ese conocimiento proviene de tres fuentes: los sentidos, la razón y el corazón (el amor); la conjugación de estos tres permite alcanzar el verdadero conocimiento. Pero no basta con adquirir conocimiento, también se debe poner en práctica el conocimiento y, en tercer lugar, vivir la sinceridad, entendida como la coherencia entre nuestros valores morales y nuestros actos.

La tercera parte está compuesta por dos trabajos de los autores Luis Bahamondes e Isaac Caro. El primer capítulo, escrito por Bahamondes, aborda la emergencia de los Nuevos Movimientos Religiosos (NMR) en Chile, en un contexto en que América Latina se ve compelida a dar solución a mayores niveles de desigualdad de reparto de la riqueza y la preponderancia de un individualismo consumista. Bajo las herramientas teóricas que definen a los movimientos sociales, Bahamondes describe las distintas tendencias que han tenido las teorías sociales para entender y comprender la dinámica de dichos movimientos a nivel mundial y de cómo son analizados en América Latina y en Chile en particular. El trabajo destaca el hecho de que los NMR han tendido a ser analizados como expresiones sectarias e incluso satánicas, lo que redunda en reduccionismos que impiden comprenderlos como reflejo de transformaciones mayores de orden societal, así como a nuevas formas de aproximación a lo sagrado, que en algunos casos tienen continuidad con tradiciones religiosas de las cuales proviene (como el cristianismo, por ejemplo).

"Diálogo y conflicto en el judaísmo latinoamericano" es el segunde capítulo de esta parte escrito por el académico Isaac Caro. En el trabajo se presentan los dos enfoques que dan cuenta del paradigma de los estudios internacionales pos-Guerra Fría: choque civilizacional y diálogo civilizacional. A través de la identificación de estas categorías, Caro entrega los elementos centrales que la definen y de los autores que se identifican con una $u$ otra propuesta. A continuación, apostando por la relevancia del diálogo, se entregan antecedentes acerca de los espacios de encuentros y foros sobre diálogo que se han dado en 
los últimos 20 años y de cómo se han producido estos acercamientos en América Latina y Argentina en particular, con posterioridad a los atentados de la Asociación Mutual Israelita Argentina (AMIA) en 1994. En este marco destaca el reconocimiento que se hace de los conflictos intracomunitarios en el mundo judío, así como también el musulmán, pero pese a ello se ha logrado generar un diálogo institucionalizado, particularmente en Argentina, que puede contribuir al establecimiento de una alianza de civilizaciones y en especial a un entendimiento mutuo en el conflicto árabe-israelí.

El último capítulo de este libro da cuenta de un trabajo desarrollado por Nicole Saffie en torno a experiencias de diálogo entre jóvenes de origen árabe y judío en Chile y que sistematiza los talleres desarrollados entre julio de 2006 y febrero de 2008 con representantes de dos colegios, el Instituto Hebreo de Santiago y el Colegio Árabe. El proyecto buscaba demostrar que era posible construir instancias y procesos de entendimiento entre dos credos pero también entre dos miradas distintas sobre el mundo, que pese a sus diferencias podían construir espacios de diversidad, tolerancia y respeto entre ambas comunidades. 